\title{
ANALISIS TINGKAT KEPUASAN PENGUNJUNG TERHADAP LAYANAN REKREASI DUNIA FANTASI PT TAMAN IMPIAN JAYA ANCOL JAKARTA UTARA
}

\author{
Oleh: \\ Resty Nidya Astuti ${ }^{1}$ \\ Akhmad Sefudin ${ }^{2}$ \\ Program Studi Pendidikan Ekonomi \\ Fakultas Ilmu Pendidikan dan Pengetahuan Sosial \\ Universitas Indraprasta PGRI \\ Email: \\ azure_resty@yahoo.com ${ }^{1}$; \\ sefudinakhmad@gmail.com²
}

\begin{abstract}
ABSTRAK
Penelitian ini bertujuan untuk mengetahui kualitas pelayanan kepuasan pengunjung yang berekreasi di Dunia Fantasi PT Taman Impian Jaya Ancol, Jakarta Utara, selain itu penulis berharap agar pembaca lebih dapat mengetahui bagaimana kepuasan pengunjung terhadap layanan rekreasi Dunia Fantasi PT Taman Impian Jaya Ancol Jakarta Utara. Penelitian ini bersifat kualitatif dengan pendekatan deskriptif. Teknik pengumpulan data menggunakan kuesioner yang disebarkan kepada pengunjung sesuai dengan keadaan subjek yang sebenarnya, metode rentang skala untuk mengetahui kualitas pelayanan dan metode analisis GAP untuk mengetahui kepuasan pengunjung. Setelah penulis mengetahui kepuasan pengunjung terhadap layanan rekreasi Dunia Fantasi akhirnya penulis menarik kesimpulan bahwa kualitas pelayanan yang ada di Dunia Fantasi sudah sangat baik, kualitas pelayanan yang sudah sangat baik membuat pengunjung merasakan sangat puas karena telah berekreasi di Dunia Fantasi.
\end{abstract}

Kata Kunci: Kualitas Pelayanan, Kepuasan Pengunjung, Dunia Fantasi

\section{A. PENDAHULUAN}

Taman Impian Jaya Ancol atau biasa disebut Ancol adalah kawasan wisata terpadu yang dikembangkan oleh PT. Pembangunan Jaya Ancol Tbk yang menyediakan banyak pilihan bagi masyarakat untuk berekreasi. Dengan kepemilikan saham $72 \%$ oleh Pemda DKI Jakarta dan $18 \%$ oleh PT. Pembangunan Jaya Ancol dan 10\% oleh Publik (masing-masing dibawah 5\% kepemilikan), Ancol selalu berupaya memenuhi berbagai kebutuhan masyarakat dibidang wisata dan rekreasi. Daya pikat ancol memancar dari berbagai destinasi wisata yang dimilikinya. Sesuai namanya, Taman Impian, sejumlah wahana di ancol menawarkan pengalaman ala dunia mimpi. Beberapa produk rekreasi yang ditawarkan dan telah dikenal oleh masyarakat pada umumnya adalah Taman Pantai, Dunia Fantasi, Atlantis, Seaworld, Gelanggang Samudera, Pantai Seni. 
Sedangkan Produk Resort yang ditawarkan yakni Putri Duyung, Pulau Bidadari, dan Marina.

Dunia Fantasi sebagai salah satu unit rekreasi unggulan yang dimiliki oleh Taman Impian Jaya Ancol adalah salah satu destinasi yang banyak dikunjungi oleh masyarakat baik dari daerah Jakarta maupun di luar Jakarta, dari segala golongan usia dari anak-anak hingga dewasa, baik keluarga maupun muda-mudi. Dengan karakteristiknya sebagai theme park, Dunia Fantasi yang sering disebut Dufan, berhasil menjadi salah satu ikon wisata dan rekreasi penting di Jakarta.

Dari segi bisnis, untuk dapat bertahan dan unggul dalam persaingan kompetitif di tengah kemunculan-kemunculan pemain baru, dan kebutuhan pelanggan yang terus berubah, diperlukan langkah dan strategi pemasaran yang efektif. Diperlukan adanya nilai tambah untuk dapat terus unggul dalam persaingan dunia bisnis. Sebagai destinasi wisata dan rekreasi unggulan yang produk utamanya adalah jasa, menciptakan pengalaman dan juga kualitas pelayanan (Service Quality) yang terbaik adalah hal yang sangat penting dalam meraih kepuasan pengunjung.

\section{B. KAJIAN PUSTAKA}

\section{Pemasaran}

Menurut Doyle (2011) definisi pemasaran adalah proses manajemen untuk mencari keuntungan maksimal bagi pemegang saham dengan mengembangkan dan mengimplementasikan strategi untuk membangun hubungan kepercayaan dengan pelanggan melalui cara penciptaan nilai pelanggan yang tinggi dan keunggulan diferensiasi secara berkelanjutan.

\section{Kualitas Pelayanan}

Menurut Wyckof (1988) "Kualitas jasa adalah tingkat keunggulan (excellence) yang diharapkan dan pengendalian atas keunggulan tersebut untuk memenuhi keinginan pelanggan"

\section{Kepuasan Pelanggan}

Definisi menurut Kotler (1997) "Kepuasan merupakan tingkat perasaan di mana seseorang menyatakan hasil perbandingan atas kinerja produk jasa yang diterima dengan yang diharapkan”.

\section{METODE PENELITIAN}

Dalam penelitian ini penulis menggunakan metode kualitatif dengan pendekatan deskriptif. Teknik pengumpulan data menggunakan kuesioner yang disebarkan kepada pengunjung sesuai dengan keadaan subjek yang sebenarnya, metode rentang skala untuk mengetahui kualitas pelayanan dan metode analisis GAP untuk mengetahui kepuasan pengunjung. 


\section{HASIL DAN PEMBAHASAN}

\section{Kualitas pelayanan yang diberikan Dunia Fantasi Kepada Pengunjung}

Kualitas pelayanan yang diberikan Dunia Fantasi kepada pengunjung, dapat diambil dari kelima indikator yang terdapat pada kuesioner yaitu meliputi Wujud Fisik (Tangible), Kehandalan (Reliability), Ketanggapan (Responsiveness), Jaminana dan Kepastian (Assurance) dan Empati (Empathy). Untuk unsur kualitas pelayanan di atas dapat diambil sebanyak 14 butir pernyataan terdapat pada kuesioner yang telah disebarkan.

$$
\begin{aligned}
& \text { Rata }- \text { rata }(\bar{x})=\frac{\sum X_{i}}{n} \\
& \text { Rata }- \text { rata }(\bar{x})=\frac{5.809}{100} \\
& \text { Rata }- \text { rata }(\bar{x})=58,09
\end{aligned}
$$

Untuk mengetahui kualitas pelayanan yang diberikan oleh Dunia Fantasi, maka perlu dibuat rentang skala. Adapun rentang skala yang digunakan yaitu :

$$
\text { skala }=\frac{\text { Rangking tertinggi }}{\text { Jumlah kelas yang dibentuk }}
$$

Jumlah Skala Likert yang dibentuk kualitas pelayanan sebanyak 5 (lima) kelas. Untuk rangking tertinggi diperoleh dari jumlah pernyataan yang diambil untuk menjawab rumusan masalah ini yaitu 14 pernyataan, kemudian dikalikan dengan skor tertinggi pada pernyataan yaitu 5. Jadi untuk rangking tertinggi sebesar 70 .

$$
\text { skala }=\frac{70}{5}=14
$$

Setelah skala diketahui, kemudian dibuat rentang skalanya:

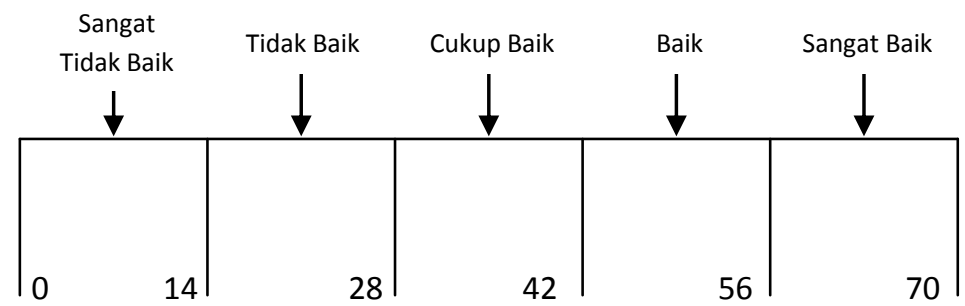

Penilaian Responden terhadap kualitas pelayanan yang diberikan oleh Dunia Fantasi dapat dilihat pada Tabel 1 dibawah ini: 
Tabel 1.

Penilaian Responden terhadap Kualitas Pelayanan yang Diberikan Dunia Fantasi

\begin{tabular}{ccc}
\hline KETERANGAN & RESPONDEN & PERSENTASE \\
\hline Sangat Tidak Baik & 0 & 0 \\
TidakBaik & 0 & 0 \\
CukupBaik & 0 & 0 \\
Baik & 40 & $40 \%$ \\
SangatBaik & 60 & $60 \%$ \\
Total & 100 & $100 \%$ \\
\hline \multicolumn{2}{c}{ Sumber: Data primer yang diolah, 2016}
\end{tabular}

Tingkat kepuasan pengunjung terhadap layanan rekreasi Dunia Fantasi

a. Bukti Fisik (Tangible)

Tabel 2.

Bukti Fisik (Tangible)

\begin{tabular}{llll} 
VARIABEL & PRESEPSI & EKSPETASI & GAP \\
\hline $\mathrm{X}_{1}$ & 4.16 & 4.36 & -0.2 \\
$\mathrm{X}_{2}$ & 4.19 & 4.16 & 0.03 \\
$\mathrm{X}_{3}$ & 4.28 & 4.25 & 0.03 \\
$\mathrm{X}_{4}$ & 4.08 & 4.29 & -0.21 \\
\hline
\end{tabular}

$\frac{\text { TOTAL }}{\text { Sumber: Data primer yang diolah, } 2016}$

$$
\text { NilaiGAPrata }- \text { rata }=-\frac{0,35}{4}=-0,087
$$

b. Kehandalan (Reliability)

Tabel 3.

Kehandalan (Reliability)

\begin{tabular}{llll}
\hline VARIABEL & PRESEPSI & EKSPETASI & GAP \\
\hline $\mathrm{X}_{5}$ & 4.25 & 4.36 & -0.11 \\
$\mathrm{X}_{6}$ & 4.18 & 4.15 & 0.03 \\
$\mathrm{X}_{7}$ & 4.18 & 4.15 & 0.03 \\
\hline TOTAL & \multicolumn{3}{c}{-0.05} \\
\hline \multicolumn{4}{c}{ Sumber: Data primer yang diolah, 2016 }
\end{tabular}

$$
\text { NilaiGAPrata }- \text { rata }=-\frac{0,5}{3}=-0,017
$$


c. Ketanggapan (Responsiveness)

Tabel 4.

Ketanggapan (Responsiveness)

\begin{tabular}{llll}
\hline VARIABLE & PRESEPSI & EKSPETASI & GAP \\
\hline $\mathrm{X}_{8}$ & 3.93 & 3.91 & 0.02 \\
$\mathrm{X}_{9}$ & 4.23 & 4.19 & 0.04 \\
$\mathrm{X}_{10}$ & 4.03 & 4.05 & -0.02 \\
\hline TOTAL & \multicolumn{3}{c}{0.04} \\
\hline \multicolumn{3}{r}{ Sumber: Data primer yang diolah, 2016 }
\end{tabular}

$$
\text { NilaiGAPrata }- \text { rata }=\frac{0,04}{3}=0,013
$$

d. Jaminan dan Kepastian (Assurance)

Tabel 5.

Jaminan dan Kepastian (Assurance)

\begin{tabular}{llll}
\hline VARIABEL & PRESEPSI & EKSPETASI & GAP \\
\hline $\mathrm{X}_{11}$ & 4.11 & 4.09 & 0.02 \\
$\mathrm{X}_{12}$ & 4.21 & 4.13 & 0.08 \\
\hline TOTAL & & & 0.1 \\
\hline
\end{tabular}

Sumber: Data primer yang diolah, 2016

$$
\text { NilaiGAPrata }- \text { rata }=\frac{0,1}{2}=0,05
$$

e. Empati (Empathy)

Tabel 6.

Empati (Empathy)

\begin{tabular}{llll}
\hline VARIABLE & PRESEPSI & EKSPETASI & GAP \\
\hline $\mathrm{X}_{13}$ & 4.25 & 4.16 & 0.09 \\
$\mathrm{X}_{14}$ & 4.01 & 4.06 & -0.05 \\
\hline TOTAL & \multicolumn{3}{c}{0.04} \\
\hline \multicolumn{4}{r}{ Sumber: Data primer yang diolah, 2016 }
\end{tabular}

$$
\text { NilaiGAPrata }- \text { rata }=\frac{0,04}{2}=0,02
$$

\section{E. SIMPULAN}

Hasil penelitian ini menunjukkan bahwa pendapat pengunjung terhadap kualitas pelayanan Dunia Fantasi sudah baik, hal tersebut terlihat dari hasil 
pendapat pengunjung sebanyak $40 \%$ berpendapat baik, $60 \%$ berpendapat sangat baik.

Hasil perhitungan dari tingkat kepuasan pengunjung terhadap layanan rekreasi Dunia Fantasi berdasarkan dari kelima indikator menunjukan bahwa indikator Tangible (Bukti Fisik) pengunjung sangat puas terhadap fasilitas yang menarik dan sarana prasarana yang nyaman bagi pengunjung, sedangkan pengunjung merasa kurang puas terhadap keamanan wahana permainan dan penampilan karyawan Dunia Fantasi. Indikator Reliability (Kehandalan) pengunjung sangat puas terhadap sistem antrian yang sudah tertib dan karyawan yang tidak mengharapkan sesuatu atas jasa yang telah diberikan, sedangkan pengunjung kurang puas terhadap pelayanan karyawan yang tidak cepat dan masih berbelit-belit. Indikator Responsiveness (Daya Tanggap) pengunjung sangat puas terhadap karyawan yang cepat tanggap terhadap kebutuhan pengunjung, informasi yang jelas dan mudah dipahami oleh pengunjung, sedangkan pengunjung kurang puas terhadap karyawan yang tidak sigap dalam kebutuhan pengunjung. Indikator Assurance (Jaminan) pengunjung sangat puas terhadap rasa aman dan keselamatan bagi pengunjung dan karyawan yang professional dan Indikator Empathy (Kepedulian) pengunjung sangat puas terhadap sambutan yang ramah oleh karyawan, sedangkan pengunjung merasa kurang puas terhadap karyawan yang tidak memberikan perhatian secara individual (Customize). 


\section{DAFTAR PUSTAKA}

Amelia S (2009). Hubungan Antara Kualitas Berita Dengan Keputusan Untuk Berlangganan Surat Kabar KOMPAS (Studi Kasus: Pelanggan Kompas Wilayah Jakarta). Universitas Indraprasta PGRI, Jakarta.

Arikunto, Suharsimi. (2006). Prosedur Penelitian Suatu Pendekatan Praktik (Edisi Revisi VI). Jakarta: PT. Rineka Cipta.

Imam Ghozali. (2006). Aplikasi Analisis Multivariate dengan Program SPSS.. Semarang: Badan Penerbit Universitas Diponegoro

Kotler, P. (2006). ManajemenPemasaranJilid 1. Jakarta. Terjemahan: Benyamin Molan. Indeks.

Keller, Keagan Kotler,P. (2008).ManajemenPemasaran. PT. Indeks

Kotler, Philip. (2009). Manajemen Pemasaran Jilid 1. Terjemahan: Benyamin Molan. Indeks. Jakarta.

Lumpiyoadi,R. (2013). Manajemen Pemasaran Jasa. Jakarta: Salemba Empat

Marjoko, 2010. Buku Modul Metode Penelitian. Jakarta: Universitas Indraprasta PGRI.

Rangkuti F. (2002). Creating Effective Marketing Plan. Jakarta: Salemba Empat

Salomon L Lithrone, M. Agung Saryatmodan Stephanie Meliana (2009). Pengaruh Dimensi Kualitas Pelayanan Terhadap Kepuasan Pelanggan Rekreasi Dunia Fantasi PT. Taman Impian Jaya Ancol. Universitas Tarumanegara, Jakarta.

Surachman Sumawihardja. dkk. (1991) Intisari Manajemen Pemasaran. Bandung: Remaja Rosdakarya Offset.

Supardi. (2013). Aplikasi Statistik Dalam Penelitian. Jakarta: Change Publication

Tjiptono Fandy. (2014). Pemasaran Jasa. Yogyakarta: CV. Andi Offset

Wibisono Dermawan. (2006). Manajemen Kinerja. Penerbit Erlangga.

Wahjono,S.I. (2010). Manajemen Pemasaran. Yogyakarta: Graha Ilmu

Wijaya T. (2011). Manajemen Kualitas Jasa. Jakarta: PT. Indeks

Zainal M EQ. (2009). Mengurai Variable Hingga Instrumen. Yogyakarta: Graha Ilmu. 